\title{
The Primary-Specialty Care Interface in Chronic Diseases: Patient and Practice Characteristics Associated with Co-Management
}

\author{
Interrelation entre services de première ligne et \\ soins spécialisés dans les cas de maladie chronique: \\ caractéristiques des patients et des cliniques associées à \\ la cogestion
}

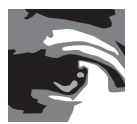

JEAN-LOUIS LAROCHELLE, PT, PHD

Physiotherapist and Teacher, École de réadaptation

Université de Montréal

Montréal, QC

DEBBIE EHRMANN FELDMAN, PT, PHD

Professor, École de réadaptation

Université de Montréal

Montréal, QC

JEAN-FREDERIC LEVESQUE, MD, PHD

Chief Executive, Senior Management Team

Bureau of Health Information

Chatswood, NSW, Australia

\begin{abstract}
Objective: Specialist physicians may act either as consultants or co-managers for patients with chronic diseases along with their primary healthcare (PHC) physician. We assessed factors associated with specialist involvement.

Methods: We used questionnaire and administrative data to measure co-management and patient and PHC practice characteristics in 702 primary care patients with common chronic diseases. Analysis included multilevel logistic regressions.
\end{abstract}


The Primary-Specialty Care Interface in Chronic Diseases: Patient and Practice Characteristics Associated with Co-Management

Results: In all, 27\% of the participants were co-managed. Persons with more severe chronic diseases and lower health-related quality of life were more likely to be co-managed. Persons who were older, had a lower socioeconomic status, resided in rural regions and who were followed in a PHC practice with an advanced practice nurse were less likely to be co-managed. Discussion: Co-management of patients with chronic diseases by a specialist is associated with higher clinical needs but demonstrates social inequalities. PHC practices more adapted to chronic care may help optimize specialist resources utilization.

\section{Résumé}

Objectif: Les médecins spécialistes peuvent agir comme consultants ou cogestionnaires pour les personnes atteintes de maladies chroniques, et ce, de pair avec le médecin de première ligne. Nous avons évalué les facteurs associés à l'implication du spécialiste.

Méthode : Nous avons employé des données administratives et des données recueillies par questionnaire pour mesurer le degré de cogestion ainsi que les caractéristiques des patients et des cliniques de première ligne auprès de 702 patients atteints de maladies chroniques fréquentes. Lanalyse comprenait une régression logistique multiniveau.

Résultats : En tout, 27 \% des participants étaient cogérés. Les personnes atteintes de maladies chroniques plus graves et dont la qualité de vie est plus affectée par la maladie ont plus de probabilités d'être cogérées. Les personnes plus âgées, qui ont un statut socioéconomique moins élevé, qui résident en milieu rural et qui sont suivies par une clinique de première ligne dotée d'une infirmière clinicienne ont moins de probabilités d'être cogérés.

Discussion : La cogestion par un spécialiste de patients atteints de maladies chroniques est associée à de plus grands besoins cliniques mais fait état d'inégalités sociales. Les cliniques de première ligne mieux adaptées pour les maladies chroniques pourraient aider à optimiser l'utilisation des ressources des spécialistes.

\section{Introduction}

Ambulatory management of chronic diseases relies mainly on the primary healthcare (PHC) setting; however, involvement of medical specialist physicians may improve process and outcomes of care for patients with chronic diseases that are within their field of expertise (O'Malley and O'Malley 2007; Smetana et al. 2007; Stange and Ferrer 2009). Specialist involvement can be of two types - co-manager or consultant - depending on whether or not the specialist provides ongoing management in addition to the primary care physician (PCP) (Forrest 2009). Specialists are involved as co-managers when they act as regular care providers for the patients, sharing responsibilities with the PCP for long-term follow-up for the patient who was referred (Forrest 2009). Specialists are consultants when their role is limited to providing diagnostic/management advice to PCPs (cognitive consultation) or performing 
diagnostic/curative technical interventions (procedural consultation), without providing ongoing management to the patient for the health problem (Forrest 2009). For example, in the case of consultation, a PCP could refer a patient with knee osteoarthritis to the orthopaedist for an injection. Once the intervention would be completed, the patient would return to the primary care provider for follow-up and would only return to see an orthopaedist when further advice or intervention would be sought. In the case of co-management, the patient would return regularly to the orthopaedist for monitoring of his arthritis and adjustment of the treatment plan. The patient would still be attended by the PCP for management of other health needs. The consultant usually requires fewer specialist visits than the co-manager; thus, acting as a consultant can free up the specialist's time to act as consultant/co-manager for more patients (Forrest 2009; Jiwa et al. 2008; Starfield 2010).

As specialist resources are limited (Fye 2004; Hanly 2004; Shipton et al. 2003; Stewart 2008), it is essential that patients receive the appropriate specialist involvement. Evaluation of need, enabling and predisposing factors (Andersen 1995) associated with type of specialist involvement would consequently be useful for clinicians, researchers and policy makers. Studies on referral and utilization patterns of specialists' services have observed that beyond clinical needs, there were social inequities and that provider and practice characteristics further predisposed and enabled these patterns (Feldman et al. 2007, 2009; Forrest et al. 2006). However, no study has addressed patient, physician or practice characteristics associated with type of specialist involvement in populations with chronic diseases. The aim of the present study was therefore to determine the clinical, socio-demographic, PCP and PHC practice characteristics associated with involvement of a medical specialist physician as a co-manager for adults with chronic diseases managed in the primary care setting.

\section{Methods}

\section{Design, recruitment and data collection}

The present study consisted of cross-sectional secondary analyses using data from a multilevel design cohort study conducted between 2006 and 2008 to assess the impact of PHC practice models on the process of care and health outcomes of patients with chronic diseases (Feldman et al. 2012; Lemieux et al. 2011). A sample of 90 PHC practices in Montréal and Montérégie regions of the province of Québec (Canada) that managed patients with chronic diseases were contacted to participate in the study. Thirty-three PHC practices referred 1,031 patients with diabetes, arthritis, congestive heart failure (CHF) or chronic obstructive pulmonary disease (COPD), of whom 776 provided written informed consent and entered the cohort. Patients were interviewed at baseline and subsequently at 6,12 and 18 months using standardized questionnaires regarding socio-demographic and clinical characteristics, utilization and quality of care and health and quality of life outcomes. We also linked patient data from the provincial physician reimbursement administrative database, including information over the period of one year prior to entry into the study until one year after entry. As in other Canadian provinces, the entire population of Quebec is covered by provincial health insur- 
The Primary-Specialty Care Interface in Chronic Diseases: Patient and Practice Characteristics Associated with Co-Management

ance, and physicians bill the province for ambulatory services rendered to patients. In Canada, patients usually require a doctor's referral to consult a specialist. The study was approved by the research ethics committees of the relevant institutions.

\section{Co-management by a specialist}

Specialist involvement was first determined using the physician reimbursement database and was defined as having at least one outpatient encounter with a relevant specialist in the 12 months prior to or after entry in the study (total period = two years). A two-year period was preferred to a one-year period because patients with co-management may not necessarily be followed yearly by the specialist. Relevant specialists considered for each diagnosis were cardiologist for CHF, respirologist for COPD, endocrinologist for diabetes and rheumatologist or orthopaedist for arthritis. Patients with specialist utilization were further classified according to the type of involvement using the following question at baseline: Which clinic mainly follows you for your (diagnosis)? (a) Your primary care clinic, where your general practitioner is; or (b) your specialized clinic, where your specialist doctor is or specialist doctors are. Those answering (b) were classified as being co-managed by a specialist. For those who answered (a), we used a second question asked at the 18-month follow-up to further determine the type of involvement: In addition to being followed by a general practitioner for your (diagnosis), are you also followed by a specialist doctor? If yes, for how many years have you been followed by the specialist? Participants who reported being followed by a specialist for at least two years were also classified as being co-managed at entry into the study. All remaining participants were not considered as being co-managed - any contact with a specialist was considered to be on a consultant basis.

\section{Independent variables}

Patients' clinical and socio-demographic characteristics (diagnosis, severity of disease, comorbidity, age, gender, region [urban = Montréal, rural = Montérégie]), highest level of education and perceived income] were measured at baseline using the survey and classified as potential need, predisposing or enabling factors for specialist services utilization (Andersen 1995; Feldman et al. 2007, 2009). Co-morbidity level was measured by the number of reported conditions from a list of 17 common chronic diseases (see Appendix available online at: www.longwoods.com/content/XXXXX). Disease-specific health-related quality of life (HRQoL) questionnaires were used as a proxy for disease severity. The following tools were used: Health Assessment Questionnaire for arthritis (Bruce and Fries 2003; Maska et al. 2011), the Minnesota Living with Heart Failure (Garin et al. 2009; Sneed et al. 2001), the Chronic Respiratory Questionnaire (Lacasse et al. 1996; Schünemann et al. 2005) and the Audit of Diabetes-Dependant Quality of Life (Bradley et al. 1999). Scores were standardized on a common scale with a mean of 50 and a standard deviation (SD) of 10, with lower scores representing more severe cases. PCP's working experience was determined based on graduation year of the physician, which was available from administrative data of the Quebec College of Physicians (licensing board). Finally, at baseline, we determined the type of practice 
arrangement (community health centre $[\mathrm{CHC}] /$ hospital-based family medicine unit, family medicine group [FMG], other physician group practice and solo practice) and the following organizational components: amount of diagnostic/therapeutic procedures available on-site, remuneration mode of physicians (fee-for-services vs. fixed salary/mixed) and presence of nurse with an innovative role (see Appendices A-D for description of all these practice variables). These practice data were determined based on the results from a survey of PHC practices completed one year prior to patient enrolment (Pineault et al. 2009).

\section{Statistical analyses}

Because of the nested sampling design and the possible clustering of patient/physician characteristics inside practices, hierarchical two-level logistic regression models with random intercept were computed to assess bivariate and multivariate associations between independent variables and co-management by a specialist. For multivariate analyses, patient's diagnosis, severity of disease, co-morbidity, age, gender, education, perceived income and PCP's experience were entered at the individual level, followed at the practice level by region and practice arrangement. To isolate the role of organizational components from practice arrangement and avoid model over-fitting, we calculated a separate model that included mode of remuneration, role of nurse and level of procedures without practice arrangement. Presence of collinearity between variables was assessed using Pearson and Spearman correlations, as well as contingency tables (see Appendices $\mathrm{E}$ and $\mathrm{F}$ for results). The likelihood ratio test was performed to assess model fit. The Wald test was used to assess if unexplained variance at patient level $\left(\tau_{0}^{2}\right)$ differed from zero, and the extended $\mathrm{R}^{2}$ formula of McKelvey and Zavoina was used to determine the explained proportion of total variation of co-management (Snijders and Bosker 1999). We used HLM 6.03 software (Scientific Software International, Lincolnwood) with the Laplace estimation method and an alpha level fixed at 0.05 for all analyses.

\section{Sensitivity analyses}

To assess robustness of our results, we repeated the modelling strategy with a definition of co-management based solely on specialist utilization pattern using the provincial physician reimbursement administrative database. There is no operational definition of specialist co-management that has been proposed in the literature for administrative data. We chose to emphasize regularity of encounter with the specialist rather than $\mathrm{PCP} /$ specialist ratio or number of encounters to capture what we considered the most important aspect of comanagement: being followed over the course of the disease. Therefore, patients who visited the relevant specialist at least once in each of the two consecutive years of available data were considered to be co-managed. Moreover, to further assess how our findings were specific to co-management, we also modelled factors associated with specialist involvement as a consultant in comparison to having no specialist utilization (patients with co-management were thus excluded from the analysis). Due to limitations in statistical power resulting from low rates 
The Primary-Specialty Care Interface in Chronic Diseases: Patient and Practice Characteristics Associated with Co-Management

of specialist involvement as a consultant, this later analysis included only patient characteristics and was therefore performed using a standard logistic regression model.

\section{Results}

At baseline, 702 patients had complete data and were included in the present analysis. There were no significant differences between participants and non-participants according to diagnosis, gender and age (results not shown). Characteristics of participants are summarized in Table 1 . The majority of participants were at least 65 years old $(54.2 \%$, minimum $=22$, maximum $=97)$, had at least one co-morbidity $(74.8 \%$, minimum $=0$, maximum $=13)$, had a PCP with at least 15 years of experience (90.0\%) and were managed in a PHC group practice $(91.5 \%)$.

TABLE 1. Characteristics of participants $(N=702)$

\begin{tabular}{|c|c|c|}
\hline Level & Characteristics & Proportion of participants $(\%)$ \\
\hline \multirow[t]{12}{*}{ Patient } & Diabetes as main diagnosis & 34.6 \\
\hline & Congestive heart failure as main diagnosis & 19.4 \\
\hline & Chronic arthritis as main diagnosis & 26.8 \\
\hline & COPD as main diagnosis & 19.3 \\
\hline & Co-morbidity, median (IQR) number & $3.0(\mid-4)$ \\
\hline & HRQoL, mean (SD) score & $50.1(10.0)$ \\
\hline & Age, mean (SD) years & $67.1(11.7)$ \\
\hline & Female gender & 54.8 \\
\hline & No high school diploma & 46.7 \\
\hline & High school diploma & 29.1 \\
\hline & Diploma $>$ high school & 24.2 \\
\hline & Income perceived less or much lesser & 22.5 \\
\hline \multirow[t]{9}{*}{ Physician practice } & Experience of PCP, mean (SD) years & $27.2(8.5)$ \\
\hline & Urban region & 59.0 \\
\hline & Solo practice & 8.5 \\
\hline & Physician group practice & 34.9 \\
\hline & Family medicine group (FMG) & 21.7 \\
\hline & Community health centre (CHC)/hospital-based family medicine unit & 35.0 \\
\hline & Fee-for-services remuneration of PCP & 65.1 \\
\hline & Nurse with innovative roles & 51.5 \\
\hline & High level of diagnostic/therapeutic procedures & 42.3 \\
\hline
\end{tabular}

* Values are in \% unless otherwise indicated.

$\mathrm{COPD}=$ chronic obstructive pulmonary disease, $\mathrm{IQR}=$ interquartile range, $\mathrm{SD}=$ standard deviation, $\mathrm{HRQ} \mathrm{L}=$ health-related quality of life, $\mathrm{PCP}=$ primary care physician. 
Overall, 314 participants (42.5\%) had at least one encounter with a specialist in the two-year study period (median visits $=3$, 1st quartile $=1$ visit, 3rd quartile $=4$ visits and maximum $=39$ visits over two years). Of these 314 participants, 193 (61.6\%) were classified based on their survey answers as co-managed by the specialist (i.e., $27.4 \%$ of the entire sample of 702). Co-managed patients had a mean number of 5.1 visits with the relevant specialist $(\mathrm{SD}=4.6$; $95 \% \mathrm{CI}=4.4-5.7)$, with $74.6 \%$ having more than two visits over the two-year period. The proportion of co-management varied between the 33 practices from $0 \%$ to $66.7 \%$ ( median $=24.3 \%$, interquartile range $=25.1 \%)$.

Table 2 (shown at www.longwoods.com/content/XXXXX) presents proportions, crude odds ratios (ORs) and adjusted ORs of being co-managed for each of the factors. Depending on the diagnosis, $10 \%$ (diabetes) to almost half (CHF) of the patients were co-managed. Probability of being co-managed doubled or tripled depending on the type of practice arrangement (from $15 \%$ in FMGs to $40 \%$ in solo practices). Unadjusted analyses indicated that probability of being co-managed was significantly lower for those with less co-morbidity, lower education, lower perceived income, living in a rural region, having diabetes, less severe state of disease or being followed in an FMG practice. Multivariate analyses further indicated that probability of being co-managed by a specialist was lower for those who were older or were being managed in a PHC practice with a nurse assuming an advanced role, but was not associated with co-morbidity.

Assessment of model fit indicated that the proportion of total variation that remained unexplained at the practice level once individual-level variables were entered in the model was $6.0 \%\left(\tau 0^{2}=0.26, p=0.001\right)$. It then decreased to $2.2 \%\left(\tau 0^{2}=0.09, p=0.019\right)$ after introducing area of residency. Only $1.2 \%\left(\tau 0^{2}=0.05, p=0.035\right)$ or $0.6 \%\left(\tau 0^{2}=0.027, p=0.090\right)$ were remaining when practice arrangement or organizational components were respectively added. The explained proportion of the total variation of the logit of being co-managed by a specialist was $13.8 \%$ for clinical factors only, $21.1 \%$ with addition of socio-demographic ones and $22.3 \%$ after including practice arrangement.

\section{Sensitivity analyses}

Overall, 191 (27.2\%) patients visited the specialist in each of the two consecutive years and were consequently classified as co-managed based solely on their utilization pattern. Similar results (not shown) were obtained using this definition of co-management, with the exception that patients managed in $\mathrm{CHCs} /$ hospital-based family medicine units demonstrated a lower probability of being co-managed compared with those managed in conventional group practices (adjusted $\mathrm{OR}=0.57,95 \% \mathrm{CI}=0.34-0.98$ ). In fact, both definitions agreed on type of specialist involvement for two out of three patients (kappa statistic $=0.68 ; p<0.001$ ), and $76.1 \%$ of the patients identified as co-managed based on the survey were also classified as comanaged in these sensitivity analyses. When we computed a multivariate model of specialist involvement as a consultant (vs. no encounter with a specialist) as a function of patient characteristics, only diagnosis and area of residency were associated with specialist involvement as a consultant. 
The Primary-Specialty Care Interface in Chronic Diseases: Patient and Practice Characteristics Associated with Co-Management

\section{Discussion}

We found that among those who had contact with a specialist, a majority had the specialist involved as a co-manager and that, overall, a quarter of adults with chronic diseases managed in PHC settings were co-managed by a physician specialist. The probability of being co-managed was associated with patient morbidity (index diagnosis and its severity), but not co-morbidity. Socio-demographic/economic characteristics of patients also accounted for a relatively important portion of the variation in being co-managed. Finally, we found that the prevalence of co-management varied between PHC practices, but that region was the main source of this variation rather than organizational practice characteristics.

Involvement of the specialist as a co-manager may be needed for health problems falling outside PCP management competencies such as severe or uncommon conditions (Starfield 2010). In contrast, for less severe and/or more common health problems, PCPs may have sufficient expertise to adequately manage the patient with the involvement of the specialist solely as a consultant to reduce clinical uncertainty or provide access to technical interventions/tests outside the PCP's scope of practice (Forrest 2009; Starfield et al. 2003). Our results are in accordance with these recommendations. Persons with CHF (a more severe condition) were most likely to be co-managed by a specialist (more than a third of patients), whereas persons with diabetes (a common chronic disease which may require less complex interventions and may be less symptomatic than the other ones) were the least likely to be co-managed (only a tenth of patients) (Deshpande et al. 2008; Halpin and Miravitlles 2006; Mosterd and Hoes 2007). Furthermore, persons who had more severe disease (lower HRQoL) were more likely to be co-managed. Co-morbidities, which add to the difficulty of patient management (Bayliss et al. 2008), would have been expected to increase probability of being co-managed. However, we found no association between co-morbidity and co-management after controlling for other covariates. Previous studies found that time to specialist consultation after onset of the chronic disease decreased with increasing burden of comorbidity (Feldman et al. 2007, 2009). Interestingly, they used the Charlson Co-morbidity Index, which also captures the severity of co-morbidities by weighting them according to their mortality (Charlson et al. 1987). There is currently no gold standard for measuring co-morbidity (Alibhai et al. 2008; Valderas et al. 2009), and for practical reasons, we created our own index limited to a co-morbidity count. Perhaps severity rather than quantity of co-morbidities may be the actual driver of the decision-making process to involve specialists in chronic disease care. Further research is thus needed to clarify the true impact of co-morbidity on specialist involvement in ambulatory patients with chronic diseases and help determine the best co-morbidity index to use in this research area.

We found that lower education and perceived income, as well as older age, were associated with decreased probability of being co-managed. This is consistent with findings in specialist services utilization literature (Chan and Austin 2003; Feldman et al. 2007, 2009). The present findings may reflect differences in preferences and/or barriers to specialist care (Chan and Austin 2003). However, they add to the literature indicating that even under universal health 
insurance for physician services, access to specialist care contradictorily remains prone to social inequalities among patients with different socioeconomic status (Chan and Austin 2003; Feldman et al. 2007, 2009). Our results also suggest that the probability of co-management is almost halved for patients living in rural regions compared with those in urban ones. It is possible that physicians in rural regions prioritize specialist involvement as consultants in a context of limited availability of specialized resources. Indeed, the ratio of specialists per person is four times higher in the Montréal urban area than in the Montérégie rural region (Gouvernement du Québec 2004), and it is well-documented that referral, access and utilization of specialist services decrease with lower availability of resources (Boyle et al. 2006; Chan and Austin 2003; Feldman et al. 2009; Forrest et al. 2006; Jaakkimainen et al. 2003). As these socio-demographic discrepancies accounted for a large amount of variation in being co-managed, further studies are needed to determine whether they reflect underuse versus overuse to promote health equity.

Experience of the PCP could affect the decision to refer to a specialist (Feldman et al. 2007, 2009; Forrest et al. 2006). However, physician experience (PCP or specialist) may not affect the type of involvement desired (Swarztrauber and Vickrey 2004) and our results are in accordance with this. Further research on attitudes and beliefs of physicians is needed to better understand the decision-making process leading to co-management.

Consistent with the literature suggesting that $\mathrm{PHC}$ practice characteristics account for only $5 \%-10 \%$ of specialist services referral and utilization (Forrest et al. 2006; Sullivan et al. 2005), we found that PHC practice characteristics may account for a limited amount of total variation of specialist co-management. Our results suggest that practice models with more attributes valued for chronic care (e.g., teamwork, increased accessibility, networking activities with community), such as FMGs and CHCs/hospital-based family medicine units, may be associated with less patient co-management, contrarily to those with lesser ones, such as solo or conventional group practices (Adams et al. 2007; Dennis et al. 2008; Levesque et al. 2012; Stange et al. 2010). However, having a nurse with an innovative role (e.g., practice nurse) sharing clinical activities with physicians may contribute significantly to explaining these findings. Indeed, we found that patients who were managed in practices that had a nurse in an innovative role (e.g., FMGs and CHCs/hospital-based family medicine units) were less likely to be co-managed than those in solo and conventional group practices (who typically do not have nurses in these positions). In accordance with the literature, we did not find an association between physician remuneration mode and co-management (Swarztrauber and Vickrey 2004).

\section{Limitations}

Our study did not assess the quality of collaboration with the specialist, health outcomes or appropriateness of co-management. Practices that participated in the study likely have PCPs with favourable attitudes towards research and management of chronic diseases. Thus, differences observed between practices participating in our study may be less than true dif- 
The Primary-Specialty Care Interface in Chronic Diseases: Patient and Practice Characteristics Associated with Co-Management

ferences in the entire population of PHC practices. Our context is one in which all residents are insured for medical care and self-referral is limited. Thus, there may be limits in terms of generalization to healthcare systems with different accessibility to specialist services. Finally, this study addressed only physician specialist involvement. Therefore, results may not apply to paramedical specialists' involvement such as dieticians for diabetes or physiotherapists for arthritis patients.

\section{Conclusions}

About one-fourth of patients with chronic diseases managed in the primary care setting are also co-managed by a medical specialist physician. Severity of the index condition is strongly associated with being co-managed by a specialist. Younger persons, those living in urban regions and those with higher level of education and financial means were further more likely to be co-managed. Organizational practice characteristics may account only for a limited amount of variation in distribution of co-management among patients, and interdisciplinary group practice involving a nurse with an innovative role may decrease co-management by a specialist. Outcome research studies are obviously needed to determine whether type of specialist involvement (consultant vs. co-manager) relates to different outcomes for persons with chronic diseases beyond the difference in frequency of contacts with the specialist.

Correspondence may be directed to: Jean-Louis Larochelle, PT, PhD, Coordonnateur pédagogique au programme QPP, Professeur adjoint de clinique, Physiothérapie, École de réadaptation - Faculté de médecine, Université de Montréal; tel.: 514-343-6111 ext. 17261; e-mail: jean-louis.larochelle@ umontreal.ca.

\section{References}

Adams, S.G., P.K. Smith, P.F. Allan, A. Anzueto, J.A. Pugh and J.E. Cornell. 2007."Systematic Review of the Chronic Care Model in Chronic Obstructive Pulmonary Disease Prevention and Management." Archives of Internal Medicine 167(6): 551-61.

Alibhai, S.M.H., M. Leach, G.A. Tomlinson, M.D. Krahn, N.E. Fleshner and G. Naglie. 2008. “Is There an Optimal Comorbidity Index for Prostate Cancer?" Cancer 112(5): 1043-50.

Andersen, R.M. 1995. "Revisiting the Behavioral Model and Access to Medical Care: Does It Matter?" Journal of Health and Social Behavior 36(1): 1-10.

Bayliss, E.A., A.F. Edwards, J.F. Steiner and D.S. Main. 2008. “Processes of Care Desired by Elderly Patients with Multimorbidities." Family Practice 25(4): 287-93.

Boyle, E., E.M. Badley and R.H. Glazier. 2006.“The Relationship between Local Availability and First-Time Use of Specialists in an Arthritis Population." Canadian Journal of Public Health 97(3): 210-13.

Bradley, C., C. Todd, T. Gorton, E. Symonds, A. Martin and R. Plowright. 1999.“"The Development of an Individualized Questionnaire Measure of Perceived Impact of Diabetes on Quality of Life: The ADDQoL." Quality of Life Research 8: 79-91.

Bruce, B. and J.F. Fries. 2003. “The Stanford Health Assessment Questionnaire: A Review of Its History, Issues, Progress, and Documentation." Journal of Rheumatology 30: 167-78. 
Chan, B.T.B. and P.C. Austin. 2003."Patient, Physician, and Community Factors Affecting Referrals to Specialists in Ontario, Canada: A Population-Based, Multi-Level Modelling Approach." Medical Care 41(4): 500-11.

Charlson, M.E., P. Pompei, K.L. Ales and C.R. MacKenzie. 1987. "A New Method of Classifying Prognostic Comorbidity in Longitudinal Studies: Development and Validation." Journal of Chronic Disease 40(5): 373-83.

Dennis, S.M., M. Zwar, R. Griffiths, M. Roland, I. Hasanqbal, P.D. Gawaine and M. Harris. 2008. “Chronic Disease Management in Primary Care: From Evidence to Policy." Medical Journal of Australia 188(8 Suppl): S53-56.

Deshpande, A.D., M. Harris-Hayes and M. Schootman. 2008. “Epidemiology of Diabetes and Diabetes-Related Complications." Journal of Physical Therapy 88(11): 1254-64. doi: 10.2522/ptj.20080020.

Feldman, D.E., S. Bernatsky, J. Haggerty, K. Leffondre, P. Tousignant, Y. Roy et al. 2007. “Delay in Consultation with Specialists for Persons with New-Onset Rheumatoid Arthritis: A Population-Based Study." Arthritis and Rheumatism 57(8): 1419-25.

Feldman, D.E., J.F. Lévesque, V. Lemieux, A. Tourigny, J.P. Lavoie and P. Tousignant. 2012. “Primary Healthcare Organization and Quality-of-Life Outcomes for Persons with Chronic Disease." Healthcare Policy 7(3): 59-72.

Feldman, D.E., Y. Xiao, S. Bernatsky, J. Haggerty, K. Leffondré, P. Tousignant et al. 2009. “Consultation with Cardiologists for Persons with New-Onset Chronic Heart Failure: A Population-Based Study." Canadian Journal of Cardiology 25(12): 690-94. doi: 10.1016/s0828-282x(09)70528-8.

Forrest, C.B. 2009. “A Typology of Specialists' Clinical Roles." Archives of Internal Medicine 169(11): 1062-68.

Forrest, C.B., P.A. Nutting, S. von Schrader, C. Rohde and B. Starfield. 2006. "Primary Care Physician Specialty Referral Decision Making: Patient, Physician, and Health Care System Determinants." Medical Decision Making 26(1): 76-85. doi: 10.1177/0272989x05284110.

Fye, B.W. 2004. “Cardiology's Workforce Shortage: Implications for Patient Care and Research.” Circulation 109(7): $813-16$.

Garin, O., M. Ferrer, À. Pont, M. Rué, A. Kotzeva, I. Wiklund et al. 2009. “Disease-Specific Health-Related Quality of Life Questionnaires for Heart Failure: A Systematic Review with Meta-Analyses." Quality of Life Research 18(1): 71-85. doi: 10.1007/s11136-008-9416-4.

Gouvernement du Québec. 2004. Consommation et offre normalisées des services offerts par les médecins. Québec: Ministère de la Santé et des Services Sociaux, Logiciel CONSOM.

Halpin, D.M.G. and M. Miravitlles. 2006. “Chronic Obstructive Pulmonary Disease." Proceedings of the American Thoracic Society 3(7): 619-23. doi: 10.1513/pats.200603-093SS.

Hanly, J.G. 2004. "Physician Resources and Postgraduate Training in Canadian Academic Rheumatology Centers: A 5-Year Prospective Study." Journal of Rheumatology 31(6): 1200-05.

Jaakkimainen, L., B. Shah and A. Kopp. 2003. “Chapter 9: Sources of Physician Care for People with Diabetes." In J.E. Hux, G.L. Booth, P.M. Slaughter and A. Laupacis, eds., Diabetes in Ontario: An ICES Practice Atlas. Institute for Clinical Evaluative Sciences, Toronto.

Jiwa, M., M. Gordon, H. Arnet, H. Ee, M. Bulsara and B. Colwell. 2008. "Referring Patients to Specialists: A Structured Vignette Survey of Australian and British GPs." BMC Family Practice 9(1): 2.

Lacasse, Y., E. Wong, G.H. Guyatt, D. King, D.J. Cook and R.S. Goldstein. 1996. “Meta-Analysis of Respiratory Rehabilitation in Chronic Obstructive Pulmonary Disease." Lancet 348: 1115-19.

Lemieux, V., J.F. Lévesque and D. Feldman. 2011. “Are Primary Healthcare Organizational Attributes Associated with Patient Self-Efficacy for Managing Chronic Disease?" Healthcare Policy 6(4): e89-105.

Levesque, J.-F., R. Pineault, M. Hamel, D. Roberge, C. Kapetanakis, B. Simard et al. 2012.“Emerging

Organisational Models of Primary Healthcare and Unmet Needs for Care: Insights from a Population-Based Survey in Quebec Province." BMC Family Practice 13(1): 66.

Maska, L., J. Anderson and K. Michaud. 2011. "Measures of Functional Status and Quality of Life in Rheumatoid Arthritis: Health Assessment Questionnaire Disability Index (HAQ), Modified Health Assessment Questionnaire (MHAQ), Multidimensional Health Assessment Questionnaire (MDHAQ), Health Assessment Questionnaire II (HAQ-II), Improved Health Assessment Questionnaire (Improved HAQ), and Rheumatoid Arthritis Quality of Life (RAQoL)." Arthritis Care and Research 63(S11): S4-13. doi: 10.1002/acr.20620. 


\section{The Primary-Specialty Care Interface in Chronic Diseases: Patient and Practice Characteristics}

Associated with Co-Management

Mosterd, A. and A.W. Hoes. 2007. “Clinical Epidemiology of Heart Failure." Heart 93(9): 1137-46. doi: 10.1136/ hrt.2003.025270.

O'Malley, P.G. and A.S. O'Malley. 2007. "Studies Comparing Quality of Care by Specialty: Valid, Relevant, or Neither?" Archives of Internal Medicine 167(1): 8-9.

Pineault, R., J.-F. Levesque, D. Roberge, M. Hamel, P. Lamarche and J. Haggerty. 2009. “Accessibility and Continuity of Care: A Study of Primary Healthcare in Québec. Gouvernement du Québec Centre de recherche de l'Hôpital Charles LeMoyne. <http://www.inspq.qc.ca/pdf/publications/911_ServicesPremLigneANGLAIS. pdf>.

Schünemann, H.J., R. Goldstein, M.J. Mador, D. McKim, E. Stahl, M. Puhan et al. 2005. “A Randomised Trial to Evaluate the Self-Administered Standardised Chronic Respiratory Questionnaire." European Respiratory Journal 25(1): 31-40. doi: 10.1183/09031936.04.00029704.

Shipton, D., E.M. Badley and N.N. Mahomed. 2003. "Critical Shortage of Orthopaedic Services in Ontario, Canada." The Journal of Bone and Joint Surgery 85(9): 1710-15.

Smetana, G.W., B.E. Landon, A.B. Bindman, H. Burstin, R.B. Davis, J. Tjia and E.C. Rich. 2007.“A Comparison of Outcomes Resulting from Generalist vs. Specialist Care for a Single Discrete Medical Condition: A Systematic Review and Methodologic Critique." Archives of Internal Medicine 167(1): 10-20.

Sneed, N.V., S. Paul, Y. Michel, A. VanBakel and G. Hendrix. 2001. “Evaluation of 3 Quality of Life Measurement Tools in Patients with Chronic Heart Failure." Heart Lung 30(5): 332-40. doi: 10.1067/mhl.2001.118303.

Snijders, T.A.B. and R.J. Bosker. 1999. Discrete Dependent Variables Multilevel Analysis. An Introduction to Basic and Advanced Multilevel Modelling (pp. 207-238). Thousand Oaks, CA: Sage Publications.

Stange, K.C. and R.L. Ferrer. 2009. “The Paradox of Primary Care.” Annals of Family Medicine 7(4): 293-99. doi: 10.1370/afm.1023.

Stange, K.C., P.A. Nutting, W.L. Miller, C.J. Carlos, B.F. Crabtree, S.A. Flocke and J.M. Gill. 2010.“Defining and Measuring the Patient-Centered Medical Home." Journal of General Internal Medicine 26(5): 601-12.

Starfield, B. 2010. "Primary Care, Specialist Care, and Chronic Care: Can They Interlock?” Chest 137(1): 8-10. doi: 10.1378/chest.09-1441.

Starfield, B., K.W. Lemke, T. Bernhardt, S.S. Foldes, C.B. Forrest and J.P. Weiner. 2003. “Comorbidity: Implications for the Importance of Primary Care in 'Case' Management." Annals of Family Medicine 1(1): 8-14.

Stewart, A.F. 2008. “The United States Endocrinology Workforce: A Supply-Demand Mismatch." Journal of Clinical Endocrinology and Metabolism 93(4): 1164-66. doi: 10.1210/jc.2007-1920.

Sullivan, C.O., R.Z. Omar, G. Ambler and A. Majeed. 2005. “Case-Mix and Variation in Specialist Referrals in General Practice." British Journal of General Practice 55(516): 529-33.

Swarztrauber, K. and B. Vickrey. 2004.“Do Neurologists and Primary Care Physicians Agree on the Extent of Specialty Involvement of Patients Referred to Neurologists?" Journal of General Internal Medicine 19(6): 654-61. doi: 10.1111/j.1525-1497.2004.30535.x.

Valderas, J.M., B. Starfield, B. Sibbald, C. Salisbury and M. Roland. 2009. “Defining Comorbidity: Implications for Understanding Health and Health Services." Annals of Family Medicine 7(4): 357-63. doi: 10.1370/afm.983. 